\title{
Improved \\ Electrocatalytic Water Splitting Reaction on CeO2(111) by Strain Engineering: A DFT+U Study
}

\author{
Wu, Tiantian; Vegge, Tejs; Hansen, Heine Anton
}

Published in:

ACS Catalysis

Link to article, DOI:

10.1021/acscatal.9b00203

Publication date:

2019

Document Version

Peer reviewed version

Link back to DTU Orbit

Citation $(A P A)$ :

Wu, T., Vegge, T., \& Hansen, H. A. (2019). Improved Electrocatalytic Water Splitting Reaction on CeO2(111) by Strain Engineering: A DFT+U Study. ACS Catalysis, 9, 4853-4861. https://doi.org/10.1021/acscatal.9b00203

\section{General rights}

Copyright and moral rights for the publications made accessible in the public portal are retained by the authors and/or other copyright owners and it is a condition of accessing publications that users recognise and abide by the legal requirements associated with these rights.

- Users may download and print one copy of any publication from the public portal for the purpose of private study or research.

- You may not further distribute the material or use it for any profit-making activity or commercial gain

- You may freely distribute the URL identifying the publication in the public portal

If you believe that this document breaches copyright please contact us providing details, and we will remove access to the work immediately and investigate your claim 


\section{Improved Electrocatalytic Water Splitting Reaction on $\mathrm{CeO}_{2}(111)$ by Strain Engineering: A DFT $+U$ Study}

Tiantian Wu, Tejs Vegge and Heine Anton Hansen*

Department of Energy Conversion and Storage, Technical University of Denmark, Fysikvej, $2800 \mathrm{Kgs}$. Lyngby, Denmark.

*Corresponding author:

Assoc. Prof. Dr. Heine Anton HansenＥ-mail: heih@dtu.dk Tel: +45 45258211 


\section{ABSTRACT}

Ceria is a promising cathode material in Solid Oxide Electrolysis Cells (SOEC) because ceria can become a mixed electronic and ionic conductor through doping, which enables a high surface area for electrocatalysis. Here, we systemically investigate the effect of strain on the electrocatalytic water splitting reaction (WSR) for renewable hydrogen production on $\mathrm{CeO}_{2}(111)$ by using density functional theory corrected for on-site Coulomb interactions $(\mathrm{DFT}+U)$. We find tensile strain stabilizes the reduced states of ceria such as oxygen vacancies and surface hydroxyls, while compressive strain destabilizes the reduced states. These trends are explained by a downshift of the Ce 4 f orbital energy under tensile strain and agree with the larger size of the $\mathrm{Ce}^{3+}$ ion than the $\mathrm{Ce}^{4+}$ ion. Our results show that hydroxyl decomposition into $\mathrm{H}_{2}$ has the highest activation energy along the WSR pathway $\left(E_{a}\right)$ and that the free energy of hydroxyl formation $\left(\Delta \mathrm{G}_{\mathrm{H}}\right)$ prior to hydroxyl decomposition can act as a thermodynamic barrier to the WSR. Compressive strain $(<-3.0 \%)$ correlates strongly with increased WSR activity on $\mathrm{CeO}_{2}(111)$ because it reduces the total barrier $\left(\Delta \mathrm{G}_{\mathrm{H}}+\mathrm{E}_{\mathrm{a}}\right)$. Strain also effectively engineers the reaction pathway of the WSR at $\mathrm{T}>1000 \mathrm{~K}$. By comparing the total reaction barrier on different hydroxylated surfaces, the WSR is found to proceed readily via a $\mathrm{Ce}-\mathrm{H}$ intermediate on excessively hydroxylated $\mathrm{CeO}_{2}(111)$ under tensile strain because of the lower barrier, while the WSR proceeds preferentially and readily on the partially or fully hydroxylated $\mathrm{CeO}_{2}(111)$ under compressive strain. In addition, a direct mapping between the most efficient WSR pathway and strain at different operating temperatures provides a better understanding on the efficient WSR on the $\mathrm{CeO}_{2}(111)$ by strain engineering, which sheds light on electrocatalysis on oxide catalysts.

KEYWORDS: Sustainable Hydrogen Production, Ceria, Strain Effect, DFT Simulations, Descriptor Analysis 


\section{INTRODUCTION}

Production of clean fuel with zero carbon emissions can be facilitated by sustainable production of hydrogen ${ }^{1,2}$. The electrocatalysis of the water splitting reaction (WSR) powered by renewable energy (such as wind energy and solar energy) provides a promising approach to achieve this goal $^{1,2}$. Compared to low temperature electrolysis cells, solid oxide electrolysis cells (SOEC) may efficiently reduce water to hydrogen at low overpotentials by utilization of waste heat at higher temperatures. ${ }^{3-5}$ However, electrodes in SOEC are mechanically unstable because of cracking at the triple phase boundaries (TPBs) between the gas channels, the solid electrolyte and the electrode. ${ }^{4,6}$ The important scientific challenge for achieving renewable hydrogen production in SOEC is to develop an earth-abundant, stable and active catalyst, which can extend the WSR from the limiting TPBs to a two-phase boundary with a much wider surface area and promote the WSR.

As a good mixed ionic and electronic conductor, ceria $\left(\mathrm{CeO}_{2}\right)$ has been widely used in many catalytic processes not only as a support, but also as an efficient active component in redox reactions such as oxygen storage in three-way catalysts ${ }^{7-9}$, water-gas shift reaction ${ }^{10-12}$ and production of fossil fuel using solar thermochemical cycles ${ }^{13,14}$. Ceria has also attracted significant interest among the identified materials for electrocatalysis of the WSR in SOEC due to several superior properties: (i). the ceria/gas interface is accessible to both ionic and electronic carriers as well as gas molecules, which can extend the reaction zones from the TPBs to a twophase (ceria/gas) boundary ${ }^{15,16}$, (ii) the fast ionic conductivity facilitates the reaction activity of ceria. The reactions associated with $\mathrm{H}_{2}$ production, and $\mathrm{H}_{2} \mathrm{O}$ splitting on ceria have been studied extensively, demonstrating that the catalytic behavior of ceria can be influenced by its mixed valence $\mathrm{Ce}^{3+} / \mathrm{Ce}^{4+}$ redox states, the mobility of oxygen ions (oxygen vacancy diffusion) $)^{3,17,18}$ and the positive entropy contribution that is associated with the $f^{0} \rightarrow f^{1}$ transition $^{19}$.

Electrocatalysis of the WSR on ceria includes several steps ${ }^{3}$ : oxygen vacancy diffusion to the surface, water adsorption near the oxygen vacancy $\left(\mathrm{V}_{\mathrm{O}}\right)$, water dissociation into hydroxyls $\left(\mathrm{H}_{2} \mathrm{O}_{\mathrm{ads}}+2 \mathrm{Ce}^{3+}+\mathrm{V}_{\mathrm{O}}+\mathrm{O}^{2-} \rightarrow 2 \mathrm{OH}^{-}+2 \mathrm{Ce}^{3+}\right)$ and finally hydroxyl decomposition to release hydrogen $\left(2 \mathrm{OH}^{-}+2 \mathrm{Ce}^{3+} \rightarrow \mathrm{H}_{2}+2 \mathrm{Ce}^{4+}+2 \mathrm{O}^{2-}\right)$. On excessively hydroxylated ceria, however, water dissociation and release of $\mathrm{H}_{2}$ might involve the formation of a $\mathrm{Ce}-\mathrm{H}$ intermediate $\left(\mathrm{H}_{2} \mathrm{O}_{\mathrm{ads}}+2 \mathrm{Ce}^{3+}+\mathrm{V}_{\mathrm{O}} \rightarrow \mathrm{OH}^{-}+\mathrm{Ce}^{4+}+\mathrm{Ce}^{4+} \mathrm{H}^{-} \rightarrow \mathrm{H}_{2}+2 \mathrm{Ce}^{4+}+\mathrm{O}^{2-}\right)^{17}$. Both 
theoretical and experimental studies have found $\mathrm{OH}$ species ${ }^{17,20}$ play an important role in limiting the WSR activity in ceria-based catalysis and demonstrated that the rate-determining step (RDS) of the WSR on ceria is associated with the oxidation of $\mathrm{Ce}^{3+}$ to $\mathrm{Ce}^{4+}$ during hydroxyl decomposition into $\mathrm{H}_{2}{ }^{3,17}$

To overcome the limitations of hydroxyl decomposition, strain engineering is a promising approach due to its significant influence on the local atomic structure and chemical reactivity. ${ }^{21-}$ 26 Because the variation of strain is an unavoidable consequence during the fabrication of nanostructured ceria and ionic incorporation into ceria, the strain effect on ceria has been widely reported $^{25-33}$, although the focus has mostly been on oxygen formation and oxygen ionic transport. ${ }^{27-33}$ Even though impressive progress has been made on understanding reaction pathways and reaction mechanism for the WSR on ceria ${ }^{17,19,20}$, the fundamental understanding of the effect of strain on the reaction kinetics and the formation of intermediates (such as oxygen vacancies, hydroxyls and their mixed phase) that, determines the reaction pathways remains unclear. Here, the effect of strain on the formation of oxygen vacancies, hydroxyls and oxygenhydroxyl mixed phases on the $\mathrm{CeO}_{2}(111)$, as well as the effect on the activation barriers for oxygen vacancy diffusion, water dissociation into hydroxyls and the following hydroxyl decomposition is systematically investigated by performing DFT $+U$ calculations. In addition, we provide a direct mapping between the most efficient WSR pathway and strain at operating temperature. Our investigations provide insights into the strain effect on the thermodynamics of WSR intermediates and reaction kinetics.

\section{METHODS}

Spin polarized DFT calculations are performed using the Vienna Ab-initio Simulation Package $(\text { VASP })^{34,35}$, with the Perdew-Becke-Ernzerhof (PBE) functional ${ }^{36}$. The ionic cores are described by projector augmented wave method $(\mathrm{PAW})^{37}$ and the wave functions are expended in plane waves with an energy cutoff of $550 \mathrm{eV}$. The exchange and correlation is approximated including aspherical gradient corrections within the PAW augmentation spheres (using standard PAW potentials). We use the DFT $+U$ approach $^{38}$ to describe electron localization on the $4 \mathrm{f}$ states of the reduced cerium atoms. The value of effective Hubbard $U$ term used in this work is $4.5 \mathrm{eV}$, which 
has been an appropriate correction to ensure electron localization on $\mathrm{Ce}^{3+} \cdot{ }^{39-44} \mathrm{On}$ the other hand, lower values of $U$ appear to be required to match experimental reduction and $\mathrm{CO}$ adsorption energies. $^{45,46}$

Using a dense $\Gamma$-centered $8 \times 8 \times 8 \mathrm{k}$-point mesh, the calculated bulk equilibrium lattice constant of ceria is $5.497 \AA$, which is well consistent with both theoretical $\left(5.497 \AA^{26,27,42,47}\right)$ and experimental values $\left(5.411 \AA^{48}\right)$. The $\Gamma$-centered $8 \times 8 \times 8 \mathrm{k}$-point mesh is also used to calculate lattice constants of doped ceria, $\mathrm{Ce}_{3} \mathrm{MO}_{8}$, where $\mathrm{M}=\mathrm{Al}$, Ga, Ni, Pb, Pr, Gd and La. The $\mathrm{CeO}_{2}(111)$ surface $\left(\mathrm{Ce}_{12} \mathrm{O}_{24}\right)$ is built as a $2 \times 2$ repeated surface unit cell consisting of three O-Ce-O atomic layers as shown in Figure 1. The O-Ce-O atomic layer in the bottom is kept fixed in the bulk geometry. We introduce a vacuum layer with a thickness of $15 \AA$ to reduce interaction between periodic images. Both compressive (-) and tensile (+) lattice strain is applied in the $\mathrm{CeO}_{2}(111)$ plane. The $\mathrm{Ce}-\mathrm{O}$ bond lengths of strained and unstrained $\mathrm{CeO}_{2}(111)$ agree well with values reported by Capdevila-Cortada et al. ${ }^{26}$, as shown in Table S1 in the supporting information (SI). A $\Gamma$-centered $3 \times 3 \times 1 \mathrm{k}$-point mesh is used for optimization of all surfaces. Density of states are recalculated using a $\Gamma$-centered $13 \times 13 \times 1$ k-point mesh.

For the identification of transition states and activation energies for oxygen vacancy diffusion, water dissociation into hydroxyls and hydroxyl decomposition releasing $\mathrm{H}_{2}$, we use the climbing image nudged-elastic band method as implemented in VASP ${ }^{49}$ with a tolerance of $0.03 \mathrm{eV} / \AA$.
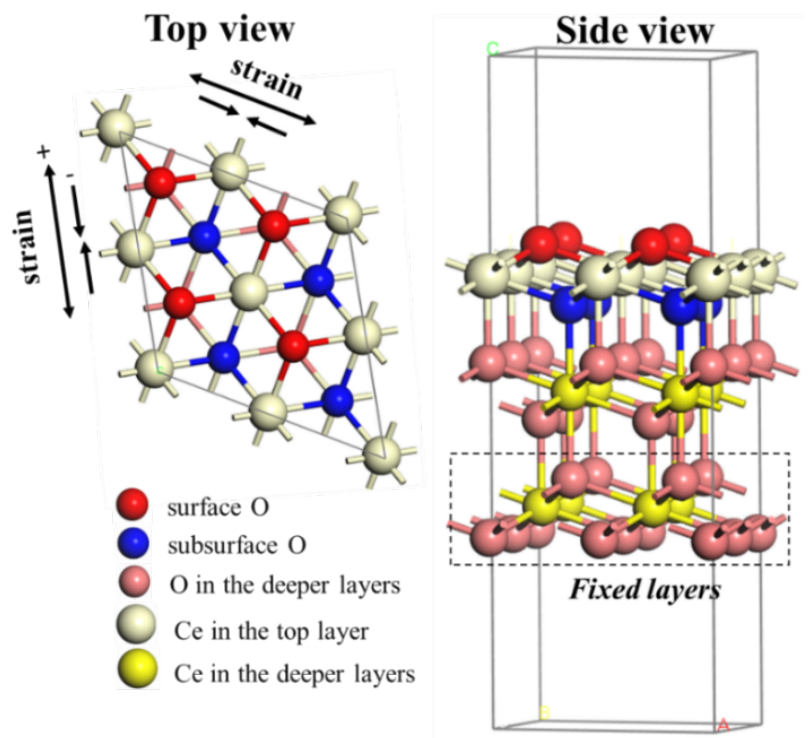

Figure 1. Atomic structure of the $\mathrm{CeO}_{2}(111)$ model slab. 


\section{RESULTS AND DISCUSSIONS}

The reaction between water, oxygen vacancies and lattice oxygen is strongly exothermic on unstrained ceria ${ }^{17,43,50,51}$

$$
\mathrm{H}_{2} \mathrm{O}_{\mathrm{ads}}+2 \mathrm{Ce}^{3+}+\mathrm{V}_{\mathrm{O}}+\mathrm{O}^{2-} \rightarrow 2 \mathrm{OH}^{-}+2 \mathrm{Ce}^{3+}
$$

while the hydroxyl decomposition to $\mathrm{H}_{2}$ has a high kinetic barrier ${ }^{17}$

$$
2 \mathrm{OH}^{-}+2 \mathrm{Ce}^{3+} \rightarrow \mathrm{H}_{2}+2 \mathrm{Ce}^{4+}+2 \mathrm{O}^{2-}
$$

However, on excessively hydroxylated ceria (above 1 monolayer $\mathrm{H}^{*}$ ), surface oxygen anions $\left(\mathrm{O}^{2-}\right)$ are unavailable and $\mathrm{H}_{2} \mathrm{O}$ dissociating on oxygen vacancies react with either subsurface $\mathrm{O}^{2-}$ or surface $\mathrm{Ce}$, through $e . .^{17}$

$$
\mathrm{H}_{2} \mathrm{O}_{\mathrm{ads}}+2 \mathrm{Ce}^{3+}+\mathrm{V}_{\mathrm{O}} \rightarrow \mathrm{OH}^{-}+\mathrm{Ce}^{4+}+\mathrm{Ce}^{4+} \mathrm{H}^{-}
$$

which is expected to significantly alter the thermodynamics of the WSR. We therefore consider the WSR on partially $\left(2 \mathrm{H}^{*}\right)$, fully $\left(4 \mathrm{H}^{*}, 1\right.$ monolayer $\left.\mathrm{H}^{*}\right)$ and excessively $\left(5 \mathrm{H}^{*}\right.$, above 1 monolayer $\left.\mathrm{H}^{*}\right)$ hydroxylated $\mathrm{CeO}_{2}(111)$ under strain in the following.

\section{Strain effect on the formation of reduced $\mathrm{CeO}_{2}(111)$}

The most likely reaction pathways via $2 \mathrm{H}^{*}, 4 \mathrm{H}^{*}$ or $5 \mathrm{H}^{*}$ surface structures include creating one oxygen vacancy in the subsurface $\left(\mathrm{V}_{\mathrm{O}}^{\text {sub }}\right)$, which then moves to the surface $\left(\mathrm{V}_{\mathrm{O}}^{\text {sur }}\right)$, followed by water adsorption, hydroxyl formation and hydrogen desorption through pathways presented in Figure 2. Along these reaction pathways, the ability to create an oxygen vacancy plays an important role in the further formation of the reduced $\mathrm{CeO}_{2}(111)$ for electrocatalysis of the WSR. As noted in Figure S1 (the locations of $\mathrm{Ce}^{3+}$ in defected ceria are presented in Figure S2 and Table S2 in the SI), creating an oxygen vacancy in the top surface and in the subsurface of pure $\mathrm{CeO}_{2}(111)$ is facile compared to creating vacancies in hydroxylated $\mathrm{CeO}_{2}(111)$. When the surface is covered by 3 hydroxyls ( $3 / 4$ monolayer hydroxyl), the oxygen vacancies in the subsurface of the expansively strained $\mathrm{CeO}_{2}(111)$ is very unstable compared to the oxygen vacancies created in bulk ceria. The formation energy of creating an oxygen vacancy in the unstrained or compressively strained $\mathrm{CeO}_{2}(111)$ follows the order: $\mathrm{V}_{\mathrm{O}}^{\text {sub }}<\mathrm{V}_{\mathrm{O}}^{\text {sur }}<\mathrm{V}_{\mathrm{O}}^{\text {sur }}\left(3 \mathrm{H}^{*}\right)<$ $\mathrm{V}_{\mathrm{O}}^{\mathrm{sub}}\left(3 \mathrm{H}^{*}\right)$. In addition, the formation energy of these oxygen vacancies decrease gradually as 
increasing of the lattice strain, consistent with Ma et al's findings ${ }^{28}$. Under tensile strain, creating one oxygen vacancy becomes much easier in hydroxylated $\mathrm{CeO}_{2}(111)$ than under compressive strain. These findings indicate that, due to the difficult formation of the oxygen vacancyhydroxyl mixed phases, the formation of fully and excessively hydroxylated $\mathrm{CeO}_{2}(111)$ require more energy than the formation of partially hydroxylated $\mathrm{CeO}_{2}(111)$.

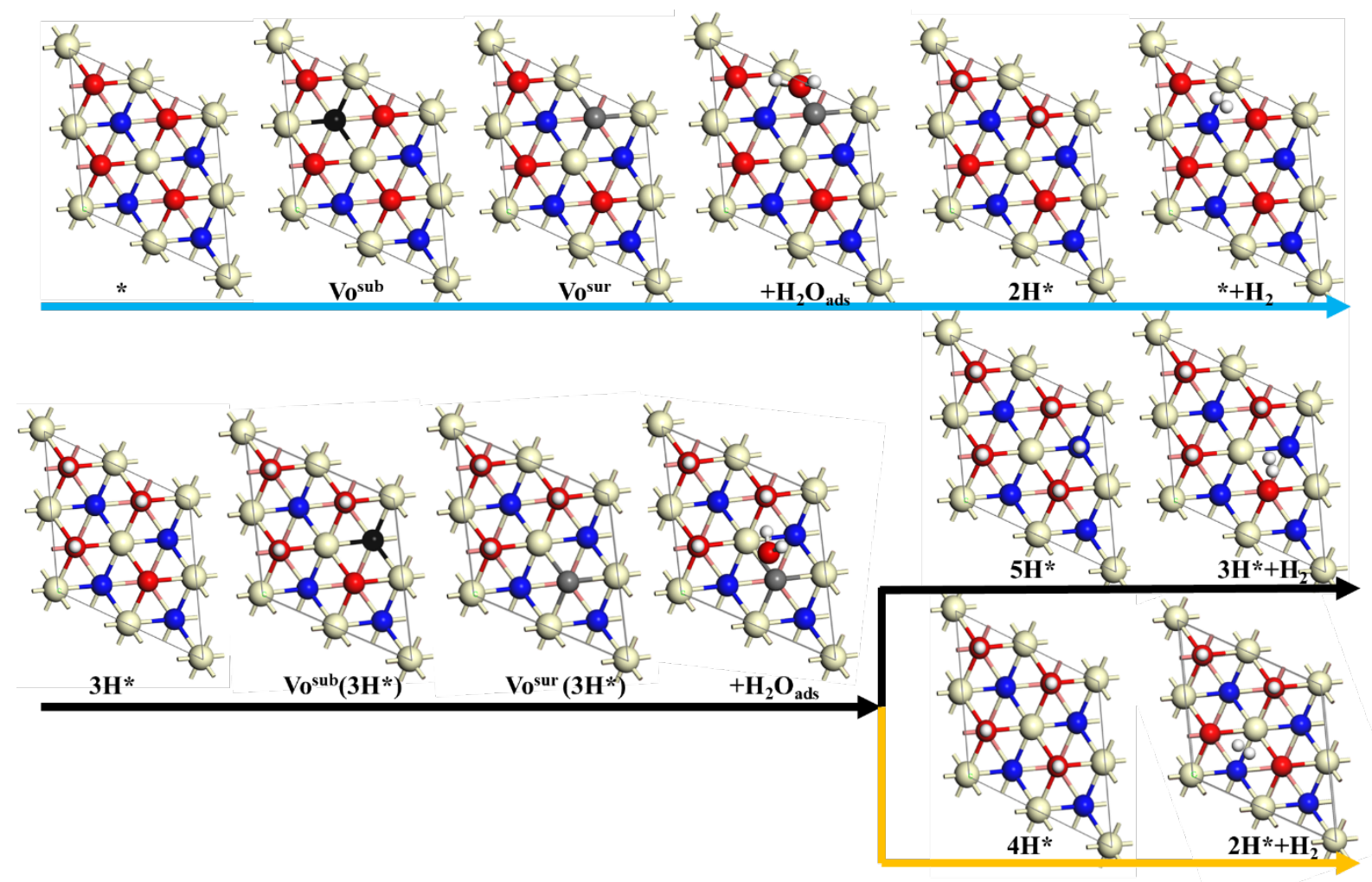

Figure 2. Schematic illustration of the hydrogen formation on the partially $\left(2 \mathrm{H}^{*}\right)$, fully $\left(4 \mathrm{H}^{*}\right)$ and excessively $\left(5 \mathrm{H}^{*}\right)$ hydroxylated $\mathrm{CeO}_{2}(111) .3 \mathrm{H}^{*}$ represents that the surface is reduced by three hydroxyls (3/4 monolayer hydroxyl). $\mathrm{V}_{\mathrm{O}}^{\text {sub }}\left(3 \mathrm{H}^{*}\right)$ and $\mathrm{V}_{\mathrm{O}}^{\text {sur }}\left(3 \mathrm{H}^{*}\right)$ represent one oxygen vacancy in the subsurface and in the top surface of the $3 \mathrm{H}^{*}$ surface, respectively. Black and grey spheres show the oxygen vacancy in the subsurface and top surface, respectively.

In Figure 3(a), we show the average hydrogen adsorption energy $\left(\mathrm{E}_{\mathrm{H}}\right)$ at different hydrogen coverages $\left(\Theta_{\mathrm{H}}\right)$ on strained $\mathrm{CeO}_{2}(111)$. For coverages up to one monolayer, hydrogen adsorption results in formation of surface hydroxyl and is exothermic. However, the hydrogen adsorption energy when forming hydroxyls on $\mathrm{CeO}_{2}(111)$ increases dramatically as the hydroxyl coverage increases from 1.0 to 1.25 , where the surface model now either has five hydroxyls in total by 
forming an unstable subsurface hydroxyl or a $\mathrm{Ce}-\mathrm{H}$ moiety in the surface. In addition, $\mathrm{E}_{\mathrm{H}}$ at each hydrogen coverage decreases as the lattice strain increase. When the lattice is expanded by $4.0 \%$, $\mathrm{E}_{\mathrm{H}}$ decreases significantly, and the formation of the excessively hydroxylated $\mathrm{CeO}_{2}(111)$ becomes as facile as the partially hydroxylated $\mathrm{CeO}_{2}(111)$ under no strain. Analysis of the projected density of states shows a downshift of the $\mathrm{Ce} 4 \mathrm{f}$ band center of $\mathrm{CeO}_{2}(111)$ under tensile strain (Figure S3), which in turn leads to higher stability of electrons localized on Ce $4 \mathrm{f}$ orbitals in expansively strained ceria. Thus, it is easier to form reduced ceria by creating oxygen vacancies or formation of hydroxyls as the lattice expands. The easier reduction of ceria under tensile strain also agrees with the larger size of the $\mathrm{Ce}^{3+}$ ion than the $\mathrm{Ce}^{4+}$ ion.

(a)

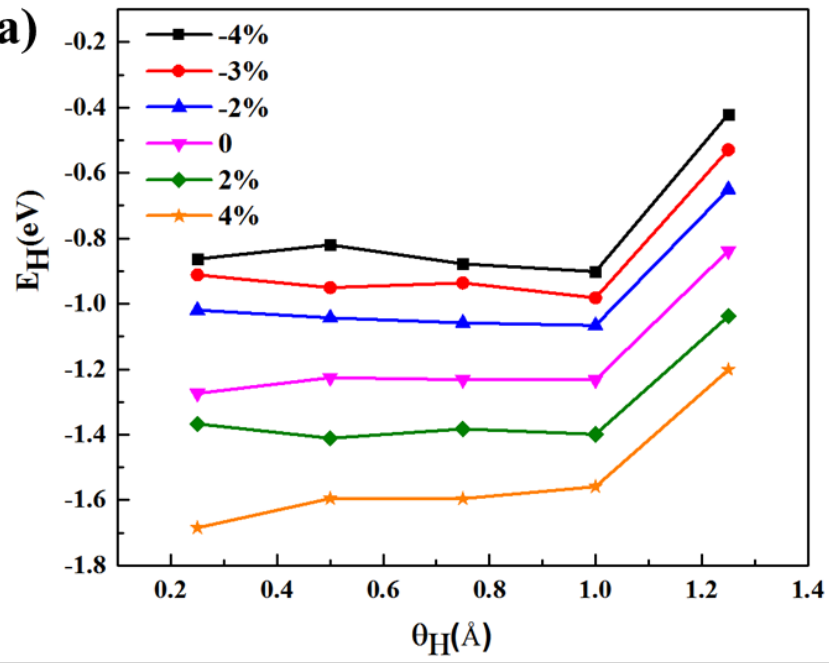

(b)

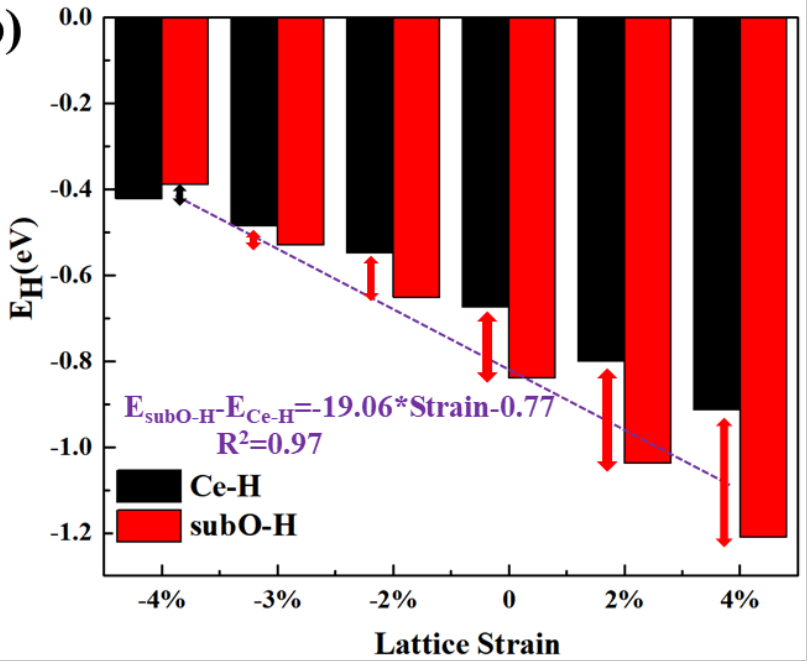

(c)
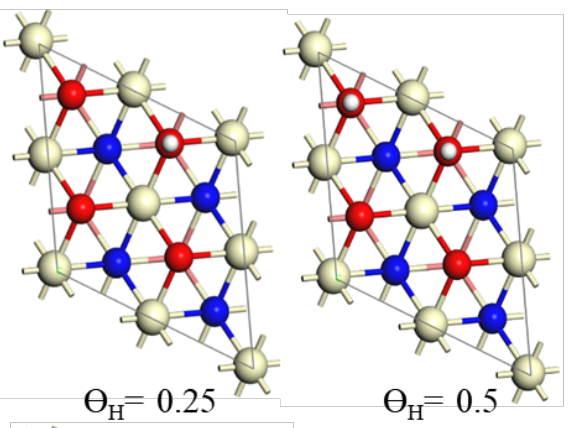

to
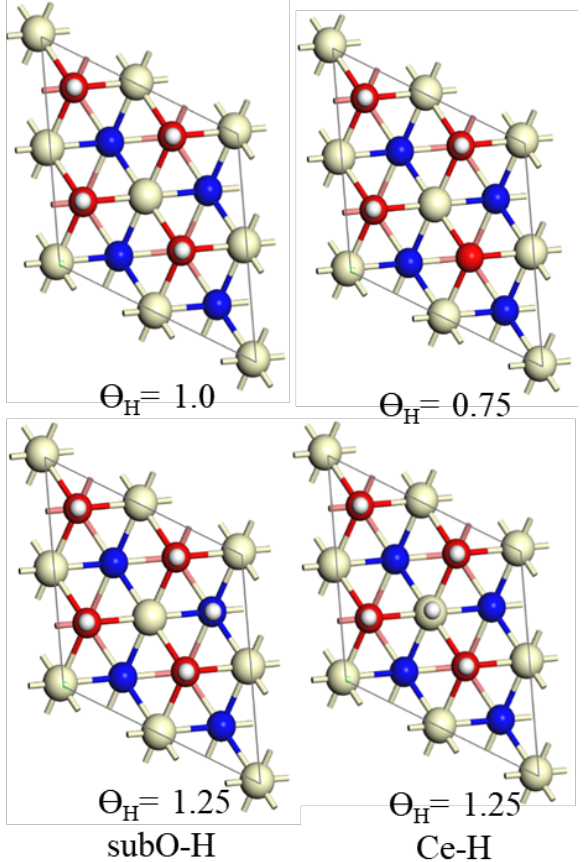

Figure 3. (a) Average hydrogen adsorption energy $\left(\mathrm{E}_{\mathrm{H}}\right)$ on strained $\mathrm{CeO}_{2}(111)$ as a function of

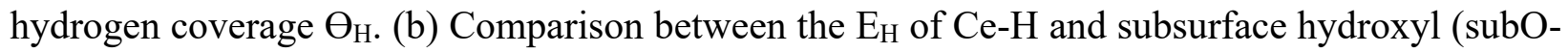


$\mathrm{H})$ at $\Theta_{\mathrm{H}}=1.25$ under different lattice strain. (c) Top views of the hydroxyls on $\mathrm{CeO}_{2}(111)$ under different hydrogen coverage.

In addition, lattice strain effectively modify the most stable configuration of the excessively hydroxylated $\mathrm{CeO}_{2}(111)$ as shown in Figure 3(b). Being an important intermediate in the hydrogen production along the highly $\mathrm{H}$ covered pathway, the excessively hydroxylated $\mathrm{CeO}_{2}(111)$ has two possible configurations: (i) $\mathrm{H}$ binding to a Ce atom in the top surface (Ce$\mathrm{H})^{17,52}$, (ii) $\mathrm{H}$ binding to an oxygen atom in the subsurface (subO-H), as shown in the Figure 3(c). For unstrained $\mathrm{CeO}_{2}(111)$, average hydrogen adsorption energy in the subO- $\mathrm{H}$ is about $0.16 \mathrm{eV}$ more negative than in the $\mathrm{Ce}-\mathrm{H}$. The energy difference between the two configurations increases with increasing the tensile strain. By contrast, the energy difference between the $\mathrm{Ce}-\mathrm{H}$ and subO$\mathrm{H}$ gets smaller with increasing compressive strain. As the surface is compressed by $4.0 \%, \mathrm{Ce}-\mathrm{H}$ rather than subO-H is the most stable configuration of the excessively hydroxylated $\mathrm{CeO}_{2}(111)$, which indicates that the $\mathrm{Ce}-\mathrm{H}$ is a likely intermediate for hydroxyl decomposition on excessively hydroxylated $\mathrm{CeO}_{2}(111)$. The strain effects on the formation of the most stable $5 \mathrm{H}^{*}$ may further adjust the hydroxyl decomposition on the $\mathrm{Ce}-\mathrm{H}$. Hydrogen formation via a $\mathrm{Ce}-\mathrm{H}$ intermediate has been reported to have a low reaction barrier and might provide an efficient reaction pathway for the WSR on ceria surfaces. ${ }^{17}$ The choice of the $U$ value affects $\mathrm{H}$ chemisorption energy on ceria. ${ }^{53} \mathrm{We}$ recently showed that reducing the $U$ value from 4.5 to $3 \mathrm{eV}$ could stabilize Ce-H by about $0.6 \mathrm{eV}$ relative to subO-H on unstrained $\mathrm{CeO}_{2}(111)^{43}$, which indicates that Figure 3(b) possibly overestimates the strain required for $\mathrm{Ce}-\mathrm{H}$ to become more stable than subO-H.

Therefore, strain effectively regulates the formation of reduced $\mathrm{CeO}_{2}(111)$ and the most stable intermediates during the WSR, which may influence the kinetics of each reaction steps along partially, fully and highly $\mathrm{H}$ covered pathways.

\section{Strain effect on the reaction barriers at each reaction steps during the WSR on reduced $\mathrm{CeO}_{2}(111)$}

Using DFT $+\mathrm{U}$ based NEB calculations, we determine the activation energy for oxygen vacancy diffusion, water dissociation, and hydroxyl decomposition along partially, fully and excessively hydroxylated pathways under different lattice strain (the $\mathrm{Ce}^{3+}$ locations are presented in Figure S2 and Table S2). There is a strong strain dependence of the barriers for oxygen 
vacancy diffusion from its most stable subsurface position to the most stable top surface position as presented in the Figure 4. The diffusion of the oxygen vacancy becomes more facile as the lattice expands, likely because of the larger space available for the diffusing oxygen ion. The efficient strain control of the ionic conductivity in ceria also gives insight into the fast ionic diffusion in doped ceria, where local tensile strain is realized.

The following step of water dissociation on the reduced $\mathrm{CeO}_{2}(111)$ is very facile, with no barrier along the partially ${ }^{17,43,54}$ and fully hydroxylated pathways $\mathrm{s}^{17,43}$ and about $0.25 \mathrm{eV}$ barrier along the excessively hydroxylated pathway under $>-3.0 \%$ strain. However, the water dissociation has an activation barrier larger than $1.0 \mathrm{eV}$ as the lattice is compressed by larger than $3.0 \%$ because the hydrogen binding to subsurface $\mathrm{O}$ becomes weak, c.f. Figure 3(b). It has been reported that the oxygen vacancies favor the formation of hydridic $\mathrm{H}$ species via $\mathrm{H}_{2}$ dissociation on ceria, where $\mathrm{H}^{-}$occupies the vacant $\mathrm{O}$ lattice positions ${ }^{55}$. By comparison, we find the presence of an oxygen vacancy in ceria favors the formation of $\mathrm{OH}$ via water dissociation, where $\mathrm{OH}$ from $\mathrm{H}_{2} \mathrm{O}$ is easily accommodated in the vacant $\mathrm{O}$ position. Our previous results show that hydroxyl-oxygen mixed configurations like $2 \mathrm{H}^{*}+\mathrm{Vo}$ or $3 \mathrm{H}^{*}+\mathrm{Vo}$ are unstable intermediates during $\mathrm{WSR}^{17}$, which easily react with adsorbed $\mathrm{H}_{2} \mathrm{O}$ to form $4 \mathrm{H}^{*}$ or $5 \mathrm{H}^{*}$, respectively, where $\mathrm{H}_{2} \mathrm{O}$ dissociating on oxygen vacancies reacts with either subsurface $\mathrm{O}^{2-}$ or surface $\mathrm{Ce}$ when the surface is fully hydroxylated. ${ }^{17,43}$

In contrast, the activation barrier for the hydroxyl decomposition, the RDS during $\mathrm{WSR}^{3,17}$, is regulated differently by strain. Firstly, we have compared the different locations of the $\mathrm{Ce}^{3+}$ ions around the hydroxyls, e.g. $2 \mathrm{H}^{*}$. We found that the configuration of $2 \mathrm{H}^{*}$ with $\mathrm{Ce}^{3+}$ as nearest neighbor to the adsorbed $\mathrm{H}$ has the most stable $\mathrm{Ce}^{3+}$ configuration as shown in Table $\mathrm{S} 3$ in the supporting information. That the relative stability of adsorbed $\mathrm{H}$ on ceria strongly depends on the $\mathrm{Ce}^{3+}$ locations agrees well with previously reported findings $\mathrm{s}^{53}$. However, we find the same transition state energy for $\mathrm{H}_{2}$ formation on the $2 \mathrm{H}^{*}$ surfaces with different $\mathrm{Ce}^{3+}$ locations, as shown in Figure S4 in the supporting information. The highest and lowest energy along the $2 \mathrm{H}^{*}$ pathway is therefore independent of the $\mathrm{Ce}^{3+}$ locations immediately before the hydroxyl decomposition into $\mathrm{H}_{2}$. The activation energy for hydroxyl decomposition on the partially, fully and excessively hydroxylated $\mathrm{CeO}_{2}(111)$ increases as the lattice expands, which arises from the stabilization of hydroxylated $\mathrm{CeO}_{2}(111)$ under tensile strain, as shown in the Figure 3. As we can 
see from Figure 4, the WSR over the fully hydroxylated $\mathrm{CeO}_{2}(111)$ has similarities to the hydroxyl formation and decomposition on the partially hydroxylated $\mathrm{CeO}_{2}(111) \cdot{ }^{17}$ A significant drop in the activation energies for hydroxyl decomposition on the excessively hydroxylated $\mathrm{CeO}_{2}(111)$ when the lattice is compressed by more than $3 \%$, is noted from Figure 4 , because the most stable intermediate for hydrogen production changes from the subO-H to $\mathrm{Ce}-\mathrm{H}$ by strain engineering. Our result are consistent with that the activation energy for breaking the $\mathrm{Ce}-\mathrm{H}$ bond is much easier than breaking an $\mathrm{O}-\mathrm{H}$ bond during hydroxyl decomposition. ${ }^{17}$ Therefore, because of the strain effects on the formation of the reduced $\mathrm{CeO}_{2}(111)$ by forming oxygen vacancies, hydroxyl-vacancy phases or hydroxyls, the activation energies at each reaction step during the WSR on the reduced $\mathrm{CeO}_{2}(111)$ are correspondingly regulated by strain, which give guidelines on how to reduce the reaction barrier at the RDS and improve the reaction efficiency of the WSR on ceria using strain engineering.

In addition, there exists a Brønsted-Evans-Polanyi (BEP) ${ }^{56}$ scaling relationship (shown in Figure S5) between the activation energy of hydrogen formation, $E_{a}$, on the different hydroxylated $\mathrm{CeO}_{2}(111)$ surfaces and the reaction energy $\left(\Delta \mathrm{E}=\mathrm{E}_{\mathrm{FS}}-\mathrm{E}_{\mathrm{IS}}\right.$, the energy difference between the initial and the final states) because of the similar geometries of the initial and the transition states. As presented in Figures S6 and S7, the calculated $E_{a}$ for strained ceria also correlates with the lattice parameter, a, which is an experimentally accessible descriptor for the activation energy of the hydroxyl decomposition. 


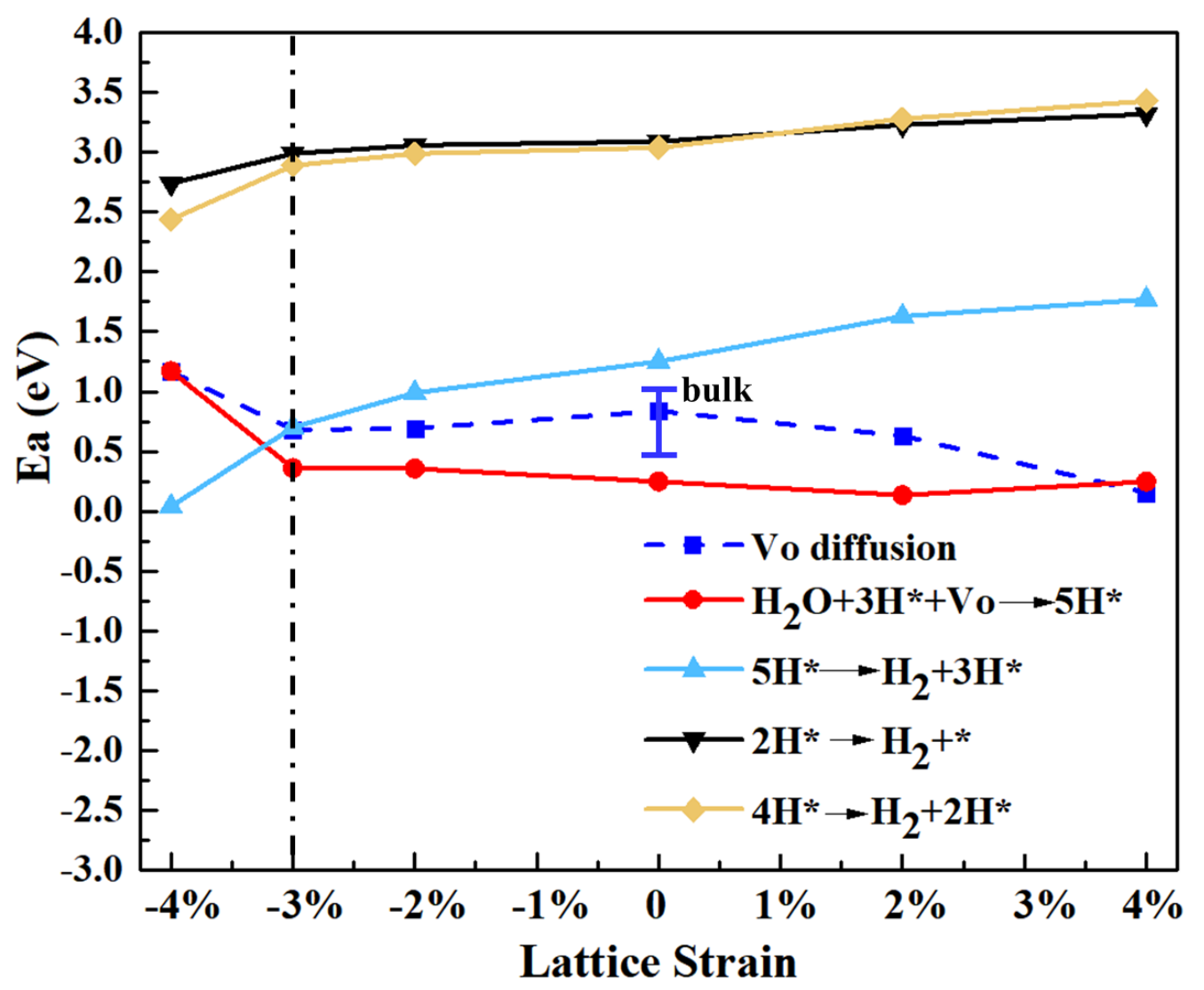

Figure 4. Reaction barriers for oxygen vacancy diffusion from the most stable subsurface position to the most stable top surface position, the formation of $5 \mathrm{H}^{*}$ via water dissociation $\left(\mathrm{H}_{2} \mathrm{O}_{\text {ads }}+3 \mathrm{H}^{*}+\mathrm{V}_{\mathrm{O}} \rightarrow 5 \mathrm{H}^{*}\right)$ as well as hydroxyl decomposition on the partially $\left(2 \mathrm{H}^{*} \rightarrow \mathrm{H}_{2}+*\right)$, fully $\left(4 \mathrm{H}^{*} \rightarrow \mathrm{H}_{2}+2 \mathrm{H}^{*}\right)$, and excessively $\left(5 \mathrm{H}^{*} \rightarrow \mathrm{H}_{2}+3 \mathrm{H}^{*}\right)$ hydroxylated $\mathrm{CeO}_{2}(111)$, under different lattice strain. The calculated diffusion barrier of an oxygen vacancy in unstrained ceria is compared to reported barriers in bulk ceria $(0.46-1.08 \mathrm{eV}) .{ }^{57}$ The water dissociation on the partially and fully hydroxylated $\mathrm{CeO}_{2}(111)$ has negligible activation energy.

\section{Strain engineering of the thermodynamics of the WSR on reduced $\mathrm{CeO}_{2}(111)$}

To calculate the relative free energy of the reduced $\mathrm{CeO}_{2}(111)$ along each reaction pathway, we use an a DFT-based thermodynamics approach described in Ref. ${ }^{17}$. First, the clean $\mathrm{CeO}_{2}(111)$ is chosen as the reference surface. Reduced $\mathrm{CeO}_{2}(111)$ surfaces then form via reactions between oxygen vacancies and water molecules at the referenced surface. In a SOEC, oxygen vacancies are produced at the anode by evolving oxygen. Oxygen vacancies then diffuse through the solid electrolyte to the cathode, where oxygen vacancies react with water to produce hydrogen through 
the WSR. The net reaction is the splitting of water into $\mathrm{H}_{2}$ and $\mathrm{O}_{2}$ driven by an external power source. The chemical potential of oxygen at the ceria cathode is chosen such that $\mathrm{H}_{2} \mathrm{O}(1 \mathrm{bar})$ and oxygen vacancies are in equilibrium with $\mathrm{H}_{2}$ (1 bar), which corresponds to the SOEC being at the equilibrium potential of the net reaction.

Here, we draw simplified free energy diagrams for hydroxyl decomposition on the partially $\left(2 \mathrm{H}^{*}\right)$, fully $\left(4 \mathrm{H}^{*}\right)$ and excessively $\left(5 \mathrm{H}^{*}\right)$ hydroxylated $\mathrm{CeO}_{2}(111)$ under different strain, at 800 (Figure 5), 1000 (Figure S8) and $1200 \mathrm{~K}$ (Figure S9). The free energy of intermediates and transition states for the full reaction pathways is given in Tables S4-6. In addition, the free energy of $2 \mathrm{H}^{*}, 4 \mathrm{H}^{*}$ and $5 \mathrm{H}^{*}$ can be fitted by experimentally measurable descriptors such as temperature (T) and the lattice parameter (a) as shown in Figure S10.

As noted in Figure 5, in the unstrained system at $800 \mathrm{~K}$, the activation barrier for the WSR on the partially, fully and excessively hydroxylated $\mathrm{CeO}_{2}(111)$ is, 3.04, 3.09, and $1.25 \mathrm{eV}$, respectively. The result shows that under a certain strain, breaking the $\mathrm{H}$ bonding to the $\mathrm{CeO}_{2}(111)$ surface becomes easier as more hydroxyls form on the $\mathrm{CeO}_{2}(111)$ surface. The WSR via a $\mathrm{Ce}-\mathrm{H}$ intermediate on the excessively hydroxylated $\mathrm{CeO}_{2}(111)$ requires the lowest activation energy, compared to the reactions on the partially and fully hydroxylated $\mathrm{CeO}_{2}(111)$. At $800 \mathrm{~K}$, the most stable reduced state is the fully hydroxylated $\mathrm{CeO}_{2}(111)$, compared to which the formation of the partially and excessively hydroxylated $\mathrm{CeO}_{2}(111)$ is unfavorable.

To evaluate the turnover frequency (TOF) of the WSR, we use the energetic span model ${ }^{58,59}$. For each reaction path over the $2 \mathrm{H}^{*}, 4 \mathrm{H}^{*}$ and $5 \mathrm{H}^{*}$ surfaces, we identify the TOF determining intermediate (TDI) and the TOF determining transition state (TDTS), which are the states along the pathway which maximize the energetic span between the TDI and the TDTS. Consider as an example unstrained $\mathrm{CeO}_{2}(111)$ at $800 \mathrm{~K}$, where the transition state for hydroxyl decomposition to $\mathrm{H}_{2}$ on the $5 \mathrm{H}^{*}$ surface has lower free energy than on the $2 \mathrm{H}^{*}$ and $4 \mathrm{H}^{*}$ surfaces, which makes the transition state for the hydroxyl decomposition to $\mathrm{H}_{2}$ on the $5 \mathrm{H}^{*}$ surface the TDTS. On the other hand, the TDI occurs with the $4 \mathrm{H}^{*}$ surface. The energetic span can then be approximated by $\delta \mathrm{E}=\mathrm{E}_{\mathrm{a}}+\Delta \mathrm{G}_{\mathrm{H}}$, where $\mathrm{E}_{\mathrm{a}}$ is the activation energy for hydroxyl decomposition and $\Delta \mathrm{G}_{\mathrm{H}}=\mathrm{G}_{\mathrm{H}}$ $G^{*}$, where $G^{*}=\min \left(\left\{G_{i}\right\}\right)$ is the free energy of the most stable reduced state of the ceria. In this way, the energetic span model includes the fact, that the excessively hydroxylated surface, which has low activation energy for $\mathrm{H}_{2}$ formation, is rather unlikely to form due to the low stability 
compared to the fully hydroxylated surface. Transition states for e.g. oxygen vacancy diffusion and water dissociation, and reduced states with both oxygen vacancies and hydroxyl are included in the energy span analysis, see Tables S4-6, but left out of Figure 5 and Figures S8 and S9 for clarity.

By strain engineering, the activation barrier $\left(\mathrm{E}_{\mathrm{a}}\right)$ for hydrogen production along each reaction pathway increases with increasing tensile strain, while $E_{a}$ decrease with increasing compressive strain. The increase in stability of reduced ceria with tensile strain and the BEP relation for hydroxyl decomposition to $\mathrm{H}_{2}$ explain this trend. The variation of $\Delta \mathrm{G}_{\mathrm{H}}$ for $2 \mathrm{H}^{*}$ with strain follows the same trend as $\mathrm{E}_{\mathrm{a}}$, because formation of the $2 \mathrm{H}^{*}$ happens through oxidation of more reduced surfaces such as $4 \mathrm{H}^{*}$. This oxidation becomes increasingly difficult with increasing tensile strain. However, $\Delta \mathrm{G}_{\mathrm{H}}$ of $5 \mathrm{H}^{*}$ varies with strain in the opposite way, where $\Delta \mathrm{G}_{\mathrm{H}}$ decreases with increasing tensile strain and increases with increasing compressive strain (Table S7). The $5 \mathrm{H}^{*}$ surface is formed by reduction of less reduced surfaces such as the $4 \mathrm{H}^{*}$ surface, which again is facilitated by tensile strain. Thus, considering the effect of strain on both $\mathrm{E}_{\mathrm{a}}$ and $\Delta \mathrm{G}_{\mathrm{H}}$, the WSR proceeds preferentially through the $5 \mathrm{H}^{*}$ surface at $800 \mathrm{~K}$ and $1000 \mathrm{~K}$. At $1200 \mathrm{~K}$, the $5 \mathrm{H}^{*}$ surface becomes very unstable, especially under compressive strain, and the formation of the $5 \mathrm{H}^{*}$ surface becomes very difficult, leading to hydrogen production preferentially proceeding over the $2 \mathrm{H}^{*}$ or $4 \mathrm{H}^{*}$ structures under $<-3 \%$ strain. Therefore, the preferred reaction pathway for the WSR on $\mathrm{CeO}_{2}(111)$ can be controlled by engineering the strain of ceria because the strain affects the formation of hydroxyls.

Overall, the fastest WSR is found at $-4.0 \%$ strain, where it preferentially proceeds through the $5 \mathrm{H}^{*}$ structure at $800 \mathrm{~K}$. At 1000 and $1200 \mathrm{~K}$, the reaction, however, proceeds faster through the $2 \mathrm{H}^{*}$ or $4 \mathrm{H}^{*}$ structures, as presented in Figures S8 and S9, respectively. The effect of temperature on the free energies of reduced $\mathrm{CeO}_{2}(111)$, synergizes with the effects of strain on the activation barriers for the WSR contributes to the variations of the best pathway for the WSR on the $\mathrm{CeO}_{2}(111)$.

A possible way to achieve compressed ceria surfaces could be through core shell particles where a thin $\mathrm{CeO}_{2}$ shell covers a suitably doped ceria core. The lattice constant of doped ceria largely decreases by incorporating ions with a smaller radius than $\mathrm{Ce}^{4+}$ as shown in Figure $\mathrm{S} 11$, where the dopant ionic radius taken from the database of ionic radii ${ }^{60}$ is compared to calculated 
lattice constants of doped ceria. A decrease of the lattice constant in doped ceria with decreasing dopant ionic radius is confirmed by experiments, ${ }^{61}$ and can be further decreased when the dopant concentration is increased. ${ }^{62}$ Thus, using dopants with smaller ionic radius than $\mathrm{Ce}^{4+}$ is possible to reach $<-3 \%$ compressive strain, which has great potential to increase the WSR activity on ceria. Doping the particle core with e.g. $\mathrm{Ga}^{3+}$ ions might lead to vacancy migration from the core to the particle surface, thereby setting up a dipole layer or space charge region. Although our theoretical model fixes the chemical potential of oxygen vacancies from the $\mathrm{H}_{2}-\mathrm{H}_{2} \mathrm{O}$ equilibrium, modifications of intermediate energies in response to the dipole layer are not included in the above treatment. However, vacancy migration from the bulk can be avoided by co-doping with small, high valence ions such as $\mathrm{Nb}^{5+}$. Migration of dopants to the surface can directly influence catalytic activity ${ }^{63}$, and we previously showed Gd dopants facilitates the formation of oxygen vacancies, hydroxyls, and hydridic $\mathrm{H}$ species at the rate-determining step ${ }^{43}$. 

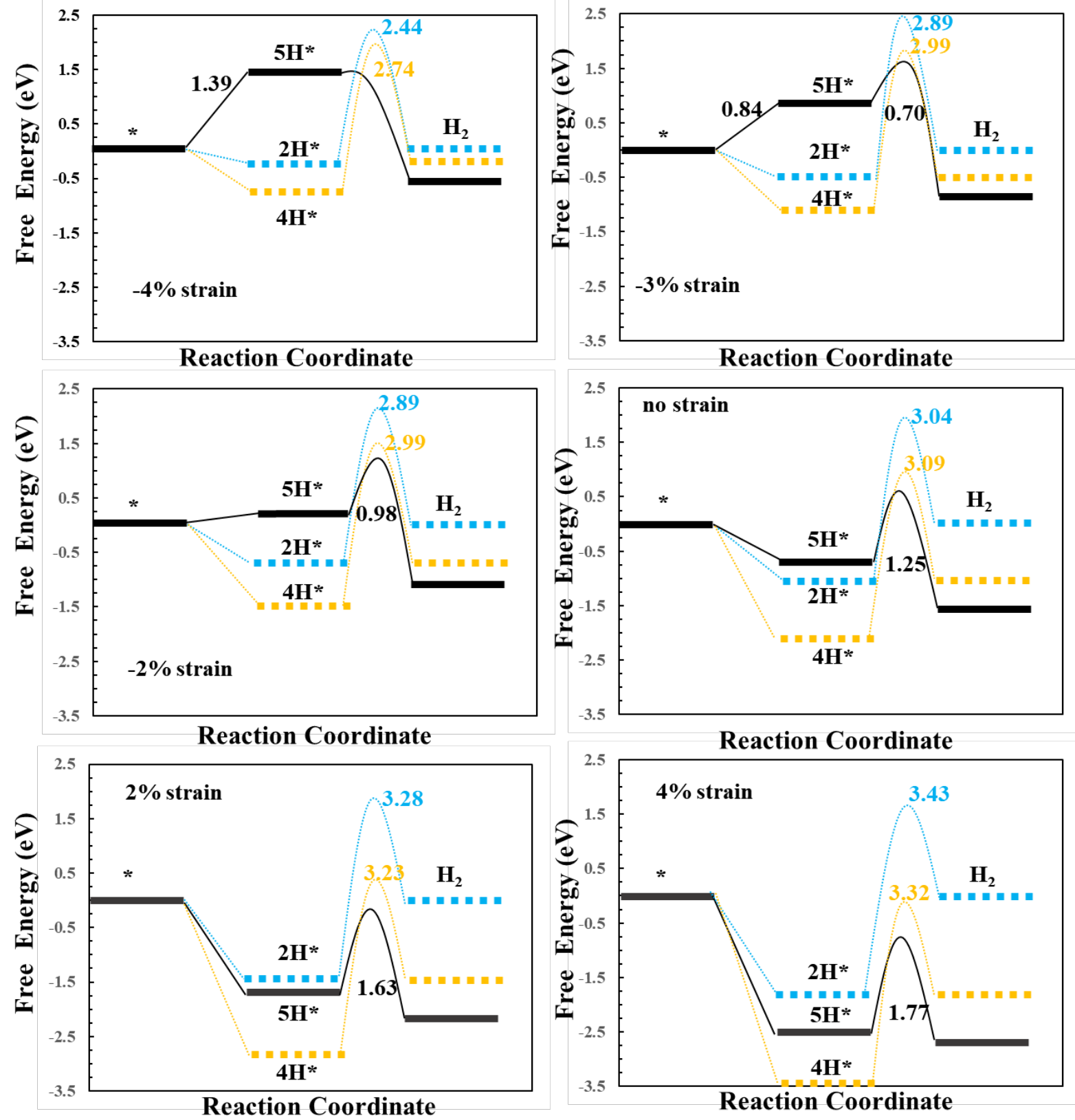

Figure 5. Simplified free energy diagrams for hydroxyl decomposition on the partially $\left(2 \mathrm{H}^{*}\right)$, fully $\left(4 \mathrm{H}^{*}\right)$ and excessively $\left(5 \mathrm{H}^{*}\right)$ hydroxylated $\mathrm{CeO}_{2}(111)$ under different strain, at $800 \mathrm{~K}$. The most efficient reaction pathway under each strain is highlighted by a solid line. 


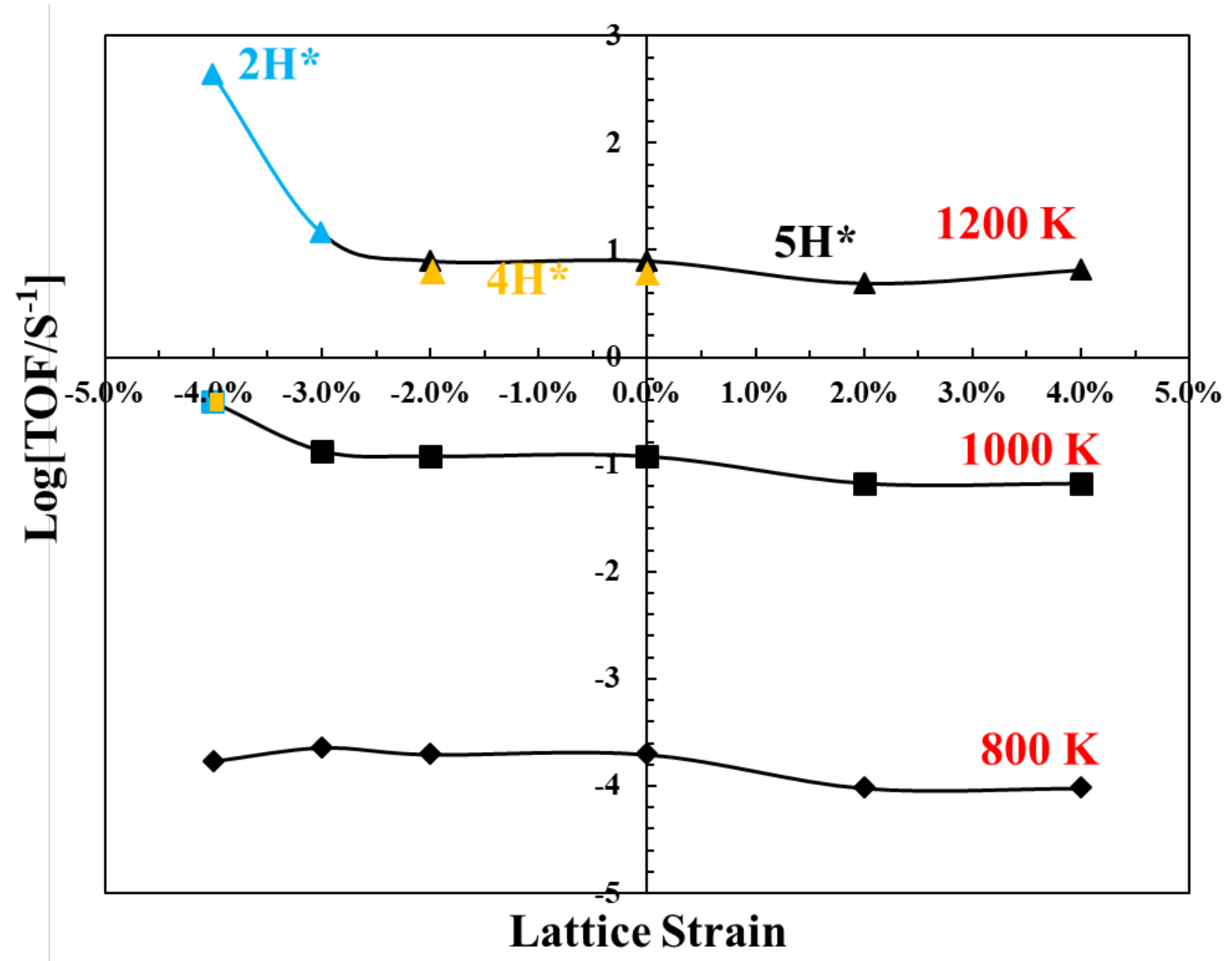

Figure 6. TOF of the WSR along the fastest pathway (the $2 \mathrm{H}^{*}, 4 \mathrm{H}^{*}$ or $5 \mathrm{H}^{*}$ path) versus lattice strain at 800,1000 and $1200 \mathrm{~K}$.

A direct mapping between the total free energy required for the WSR $\left(\Delta \mathrm{G}_{\mathrm{H}}+\mathrm{E}_{\mathrm{a}}\right)$ and strain at different temperatures gives insights to evaluate electrocatalysts of the WSR by strain engineering, as presented in Figures S12 and S13 with corresponding data listed in Table S7. The total energy span for the fastest WSR pathway increases (largely) as the strain increases, which on the other hand shows that compressive strain improves the reaction rate. At 800 and $1000 \mathrm{~K}$, the WSR with the lowest free energy span, proceeds through the excessively hydroxylated $\mathrm{CeO}_{2}(111)$ surface as shown in Figure S12. However, a significant drop in the free energy span under $-3 \%$ strain at $1200 \mathrm{~K}$ is noted from Figure S12, where the most efficient reaction proceeds on the partially hydroxylated $\mathrm{CeO}_{2}(111)$ because of a large increase of the required total free energy for the $4 \mathrm{H}^{*}$ and $5 \mathrm{H}^{*}$ pathways combined with a decrease of the energy 
span along the $2 \mathrm{H}^{*}$ pathway as noted. In addition, Figure 6 shows the forward TOF of the WSR calculated by the energetic span model

$$
T O F=\frac{k_{B} T}{h} \exp \left(\frac{-\delta E}{k_{B} T}\right)
$$

along the best pathway versus lattice strain at 800, 1000, and $1200 \mathrm{~K}$. The WSR preferentially proceeds on the excessively hydroxylated $\mathrm{CeO}_{2}(111)$ at 800 and $1000 \mathrm{~K}$, while it proceeds readily on the partially or fully hydroxylated $\mathrm{CeO}_{2}(111)$ under compressive strain at higher temperature $(>1000 \mathrm{~K})$. At high temperature, strain effectively determines the reaction pathway of the WSR. Our findings provide a direct mapping between experimentally accessible descriptors and kinetic parameters and help explain the WSR pathway under a given strain and operating temperature.

\section{CONCLUSIONS}

By using DFT $+U$ calculations, we investigated the WSR on the $\mathrm{CeO}_{2}(111)$ as well as the effect of lattice strain on the formation of the intermediates, reaction barriers and reaction pathways. It is found that the formation energy of oxygen vacancies, vacancy-hydroxyl phase and hydroxyls decrease gradually as the lattice strain is increased because of downshifts of $\mathrm{Ce} 4 \mathrm{f}$ band center, which provides a strong support for the strain engineering on the formation of intermediates during the WSR. Then the activation barriers at each reaction steps during the WSR on the reduced $\mathrm{CeO}_{2}(111)$, are correspondingly regulated because of the strain effects on formation of the reaction intermediates. Strain effectively controls the formation of the $\mathrm{Ce}-\mathrm{H}$ intermediate along the excessively hydroxylated pathway, which is proved to have a low reaction barrier for the hydroxyl decomposition.

By studying the thermodynamics of the WSR on the reduced $\mathrm{CeO}_{2}(111)$, we find that strain effectively adjusts the reaction pathway of the WSR at T $>1000 \mathrm{~K}$. The WSR proceeds via a Ce$\mathrm{H}$ intermediate on the excessively hydroxylated $\mathrm{CeO}_{2}(111)$ under tensile strain. While it proceeds preferentially and readily on the partially or fully hydroxylated $\mathrm{CeO}_{2}(111)$ under compressive strain. In addition, the free energy of hydroxyl formation $\left(\Delta \mathrm{G}_{\mathrm{H}}\right)$ prior to hydroxyl decomposition can act as a thermodynamic barrier. The sum $\left(\Delta \mathrm{G}_{\mathrm{H}}+\mathrm{E}_{\mathrm{a}}\right)$ of the hydroxyl formation energy $\left(\Delta \mathrm{G}_{\mathrm{H}}\right)$ and the activation barrier $\left(\mathrm{E}_{\mathrm{a}}\right)$ for the hydroxyl decomposition at the RDS during 
the WSR, determines the reaction rate of the hydrogen production on the strained and unstrained $\mathrm{CeO}_{2}$ (111). Our findings show that compressive strain $(<-3.0 \%)$ correlates strongly with increased WSR activity on $\mathrm{CeO}_{2}(111)$ because of the reduction of $\Delta \mathrm{G}_{\mathrm{H}}+\mathrm{E}_{\mathrm{a}}$. $\mathrm{CeO}_{2}(111)$ compressively strained by more than $3.0 \%$ has high activity for the WSR along the partially or fully hydroxylated pathways at $1200 \mathrm{~K}$. Thus, incorporating the ceria with carefully selected metal dopants, which facilitates the formation of excessively hydroxylated ceria (low $\left.\Delta \mathrm{G}_{\mathrm{H}}\right)$ and has a stable Metal-H intermediate (low $\mathrm{E}_{\mathrm{a}}$ for hydrogen formation via a Metal-H intermediate), is predicted to significantly improve the reaction efficiency of the WSR on the ceria.

Therefore, Our findings provide guides on how to improve the reaction efficiency of WSR on the $\mathrm{CeO}_{2}(111)$ by strain engineering, which can be extended to electrocatalysis on other oxide catalysis.

\section{ASSOCIATED CONTENT \\ Supporting Information:}

The supporting information includes the following:

Formation energy of an oxygen vacancy as a function of lattice strain compared to the vacancy formation in bulk ceria. $\mathrm{Ce}^{3+}$ locations in reduced ceria. Spin-polarized density of states projected on $\mathrm{O} 2 \mathrm{p}$ and $\mathrm{Ce} 4 \mathrm{f}$ orbitals. Simplified free energy diagrams for hydroxyl decomposition on the partially, fully and excessively hydroxylated $\mathrm{CeO}_{2}(111)$ surfaces under different strain, at 1000 and $1200 \mathrm{~K}$. Energy span for the most efficient WSR. Descriptor fits for the free energy of reduced ceria. BEP scaling relations for the hydroxyl decomposition pathways to form hydrogen on $\mathrm{CeO}_{2}(111)$. The correlation of $\mathrm{E}_{\mathrm{a}}$ against experimentally accessible parameters.

\section{ACKNOWLEDGMENTS}

This work was supported by the Velux Foundations through the research center V-Sustain (grant number 9455). 


\section{REFERENCES}

(1) Turner, J. A. Sustainable Hydrogen Production Processes. Science 2004, 305, 972-974.

(2) Holladay, J. D.; Hu, J.; King, D. L.; Wang, Y. An Overview of Hydrogen Production Technologies. Catal. Today 2009, 139, 244-260.

(3) Feng, Z. A.; El Gabaly, F.; Ye, X.; Shen, Z.-X.; Chueh, W. C. Fast Vacancy-Mediated Oxygen Ion Incorporation across the Ceria-Gas Electrochemical Interface. Nat. Commun. 2014, 5, 4374 .

(4) Irvine, J. T. S.; Neagu, D.; Verbraeken, M. C.; Chatzichristodoulou, C.; Graves, C.; Mogensen, M. B. Evolution of the Electrochemical Interface in High-Temperature Fuel Cells and Electrolysers. Nat. Energy 2016, 1, 15014.

(5) Sapountzi, F. M.; Gracia, J. M.; Weststrate, C. J.; Fredriksson, H. O. A.; Niemantsverdriet, J. W. Electrocatalysts for the Generation of Hydrogen, Oxygen and Synthesis Gas. Prog. Energy Combust. Sci. 2017, 58, 1-35.

(6) Hauch, A.; Mogensen, M.; Hagen, A. Ni/YSZ Electrode Degradation Studied by Impedance Spectroscopy-Effect of $\mathrm{p}\left(\mathrm{H}_{2} \mathrm{O}\right)$. Solid State Ionics 2011, 192, 547-551.

(7) Jen, H.-W.; Graham, G. W.; Chun, W.; McCabe, R. W.; Cuif, J.-P.; Deutsch, S. E.; Touret, O. Characterization of Model Automotive Exhaust Catalysts: Pd on Ceria and CeriaZirconia Supports. Catal. Today 1999, 50, 309-328.

(8) Oh, S.-H.; Hoflund, G. B. Chemical State Study of Palladium Powder and CeriaSupported Palladium during Low-Temperature CO Oxidation. J. Phys. Chem. A 2006, 110, 7609-7613.

(9) Di Monte, R.; Kašpar, J. On the Role of Oxygen Storage in Three-Way Catalysis. Top. Catal. 2004, 28, 47-57.

(10) Bunluesin, T.; Gorte, R. J.; Graham, G. W. Studies of the Water-Gas-Shift Reaction on Ceria-Supported Pt, Pd, and Rh: Implications for Oxygen-Storage Properties. Appl. Catal. B Environ. 1998, 15, 107-114.

(11) Fu, Q.; Saltsburg, H; Flytzani-Stephanopoulos, M. Active Nonmetallic Au and Pt Species on Ceria-Based Water-Gas Shift Catalysts. Science. 2003, 301, 935-938.

(12) Hilaire, S.; Wang, X.; Luo, T.; Gorte, R. J.; Wagner, J. A Comparative Study of WaterGas-Shift Reaction over Ceria-Supported Metallic Catalysts. Appl. Catal. A Gen. 2001, $215,271-278$.

(13) Otsuka, K.; Hatano, M.; Morikawa, A. Hydrogen from Water by Reduced Cerium Oxide. J. Catal. 1983, 79, 493-496.

(14) Abanades, S.; Legal, A.; Cordier, A.; Peraudeau, G.; Flamant, G.; Julbe, A. Investigation of Reactive Cerium-Based Oxides for $\mathrm{H}_{2}$ Production by Thermochemical Two-Step Water-Splitting. J. Mater. Sci. 2010, 45, 4163-4173.

(15) Chueh, W. C.; Hao, Y.; Jung, W.; Haile, S. M. High Electrochemical Activity of the 
Oxide Phase in Model Ceria-Pt and Ceria-Ni Composite Anodes. Nat. Mater. 2012, 11, $155-161$.

(16) Zhang, C.; Grass, M. E.; McDaniel, A. H.; Decaluwe, S. C.; El Gabaly, F.; Liu, Z.; McCarty, K. F.; Farrow, R. L.; Linne, M. A.; Hussain, Z.; Jackson, G. S.; Bluhm, H.; Eichhorn, B. W. Measuring Fundamental Properties in Operating Solid Oxide Electrochemical Cells by Using in Situ X-Ray Photoelectron Spectroscopy. Nat. Mater. 2010, 9, 944-949.

(17) Hansen, H. A.; Wolverton, C. Kinetics and Thermodynamics of $\mathrm{H}_{2} \mathrm{O}$ Dissociation on Reduced $\mathrm{CeO}_{2}$ (111). J. Phys. Chem. C 2014, 118, 27402-27414.

(18) Paier, J.; Penschke, C.; Sauer, J. Oxygen Defects and Surface Chemistry of Ceria: Quantum Chemical Studies Compared to Experiment. Chem. Rev. 2013, 113, 3949-3985.

(19) Naghavi, S. S.; Emery, A. A.; Hansen, H. A.; Zhou, F.; Ozolins, V.; Wolverton, C. Giant Onsite Electronic Entropy Enhances the Performance of Ceria for Water Splitting. Nat. Commun. 2017, 8, 285.

(20) Dvořák, F.; Szabová, L.; Johánek, V.; Camellone, M. F.; Stetsovych, V.; Vorokhta, M.; Tovt, A.; Skála, T.; Matolínová, I.; Tateyama, Y.; Mysliveček. J.; Fabris, S.; Matolín, V. Bulk Hydroxylation and Effective Water Splitting by Highly Reduced Cerium Oxide: The Role of O Vacancy Coordination. ACS Catal. 2018, 8, 4354-4363.

(21) Mavrikakis, M.; Hammer, B.; Nørskov, J. K. Effect of Strain on the Reactivity of Metal Surfaces. Phys. Rev. Lett. 1998, 81, 2819-2822.

(22) Tripkovic, V.; Zheng, J.; Rizzi, G. A.; Marega, C.; Durante, C.; Rossmeisl, J.; Granozzi, G. Comparison between the Oxygen Reduction Reaction Activity of $\mathrm{Pd}_{5} \mathrm{Ce}$ and $\mathrm{Pt}_{5} \mathrm{Ce}$ : The Importance of Crystal Structure. ACS Catal. 2015, 5, 6032-6040.

(23) Clark, E. L.; Hahn, C.; Jaramillo, T. F.; Bell, A. T. Electrochemical $\mathrm{CO}_{2}$ Reduction over Compressively Strained CuAg Surface Alloys with Enhanced Multi-Carbon Oxygenate Selectivity. J. Am. Chem. Soc. 2017, 139, 15848-15857.

(24) Ling, T.; Yan, D.-Y.; Wang, H.; Jiao, Y.; Hu, Z.; Zheng, Y.; Zheng, L.; Mao, J.; Liu, H.; Du, X.-W.; Jaroniec, M.; Qiao, S.-Z. Activating Cobalt(II) Oxide Nanorods for Efficient Electrocatalysis by Strain Engineering. Nat. Commun. 2017, 8, 1509.

(25) Sayle, T. X. T.; Cantoni, M.; Bhatta, U. M.; Parker, S. C.; Hall, S. R.; Möbus, G.; Molinari, M.; Reid, D.; Seal, S.; Sayle, D. C. Strain and Architecture-Tuned Reactivity in Ceria Nanostructures; Enhanced Catalytic Oxidation of $\mathrm{CO}$ to $\mathrm{CO}_{2}$. Chem. Mater. 2012, 24, 1811-1821.

(26) Capdevila-Cortada, M.; López, N. Descriptor Analysis in Methanol Conversion on Doped $\mathrm{CeO}_{2}$ (111): Guidelines for Selectivity Tuning. ACS Catal. 2015, 5, 6473-6480.

(27) Gopal, C. B.; García-Melchor, M.; Lee, S. C.; Shi, Y.; Shavorskiy, A.; Monti, M.; Guan, Z.; Sinclair, R.; Bluhm, H.; Vojvodic, A.; Chueh, W. C. Equilibrium Oxygen Storage Capacity of Ultrathin $\mathrm{CeO}_{2-\delta}$ Depends Non-Monotonically on Large Biaxial Strain. Nat. Commun. 2017, 8, 15360. 
(28) Ma, D.; Lu, Z.; Tang, Y.; Li, T.; Tang, Z.; Yang, Z. Effect of Lattice Strain on the Oxygen Vacancy Formation and Hydrogen Adsorption at $\mathrm{CeO}_{2}$ (111) Surface. Phys. Lett. A 2014, $378,2570-2575$.

(29) Rushton, M. J. D.; Chroneos, A. Impact of Uniaxial Strain and Doping on Oxygen Diffusion in $\mathrm{CeO}_{2}$. Sci. Rep. 2014, 4, 6068.

(30) Ahn, J.; Choi, S.; Yoon, K. J.; Son, J.-W.; Kim, B.-K.; Lee, J.-H.; Jang, H.-W.; Kim, H. Strain-Induced Tailoring of Oxygen-Ion Transport in Highly Doped $\mathrm{CeO}_{2}$ Electrolyte: Effects of Biaxial Extrinsic and Local Lattice Strain. ACS Appl. Mater. Interfaces 2017, 9 , 42415-42419.

(31) Rushton, M. J. D.; Chroneos, A.; Skinner, S. J.; Kilner, J. A.; Grimes, R. W. Effect of Strain on the Oxygen Diffusion in Yttria and Gadolinia Co-Doped Ceria. Solid State Ionics 2013, 230, 37-42.

(32) Kushima, A.; Yildiz, B. Oxygen Ion Diffusivity in Strained Yttria Stabilized Zirconia: Where Is the Fastest Strain? J. Mater. Chem. 2010, 20, 4809-4819.

(33) De Souza, R. A.; Ramadan, A.; Hörner, S. Modifying the Barriers for Oxygen-Vacancy Migration in Fluorite-Structured $\mathrm{CeO}_{2}$ Electrolytes through Strain: A Computer Simulation Study. Energy Environ. Sci. 2012, 5, 5445-5453.

(34) Kresse, G.; Furthmüller, J. Efficient Iterative Schemes for Ab Initio Total-Energy Calculations Using a Plane-Wave Basis Set. Phys. Rev. B 1996, 54, 11169-11186.

(35) Kresse, G.; Hafner, J. Ab Initio Molecular Dynamics for Open-Shell Transition Metals. Phys. Rev. B 1993, 48, 13115-13118.

(36) Perdew, J. P.; Burke, K.; Ernzerhof, M. Generalized Gradient Approximation Made Simple. Phys. Rev. Lett. 1996, 77, 3865-3868.

(37) Blöchl, P. E. Projector Augmented-Wave Method. Phys. Rev. B 1994, 50, 17953-17979.

(38) Dudarev, S. L.; Botton, G. A.; Savrasov, S. Y.; Humphreys, C. J.; Sutton, A. P. ElectronEnergy-Loss Spectra and the Structural Stability of Nickel Oxide: An LSDA+U Study. Phys. Rev. B 1998, 57, 1505-1509.

(39) Fabris, S.; Gironcoli, S.; Baroni, S. Vicario, G.; Balducci, G. Reply to "Comment on 'Taming Multiple Valency with Density Functionals: A Case Study of Defective Ceria.' " Phys. Rev. B 2005, 72, 237102.

(40) Farra, R.; García-Melchor, M.; Eichelbaum, M.; Hashagen, M.; Frandsen, W.; Allan, J.; Girgsdies, F.; Szentmiklósi, L.; López, N.; Teschner, D. Promoted Ceria: A Structural, Catalytic, and Computational Study. ACS Catal. 2013, 3, 2256-2268.

(41) Capdevila-Cortada, M.; García-Melchor, M.; López, N. Unraveling the Structure Sensitivity in Methanol Conversion on $\mathrm{CeO}_{2}$ : A DFT + U Study. J. Catal. 2015, 327, 5864.

(42) Su, Y.-Q.; Filot, I. A. W.; Liu, J.-X.; Tranca, I.; Hensen, E. J. M. Charge Transport over the Defective $\mathrm{CeO}_{2}$ (111) Surface. Chem. Mater. 2016, 28, 5652-5658. 
(43) Wu, T.; Deng, Q.; Hansen, H. A.;Vegge, T. Mechanism of Water Splitting on Gadolinium-Doped $\mathrm{CeO}_{2}$ (111): A DFT + U Study. J. Phys. Chem. C 2019, 123, 55075517.

(44) Su, Y.-Q.; Liu, J.-X.; Filot, I. A. W.; Zhang, L.; Hensen, E. J. M. Highly Active and Stable $\mathrm{CH}_{4}$ Oxidation by Substitution of $\mathrm{Ce}^{4+}$ by Two $\mathrm{Pd}^{2+}$ Ions in $\mathrm{CeO}_{2}(111)$. ACS Catal. 2018, 8, 6552-6559.

(45) Huang, M.; Fabris, S. CO Adsorption and Oxidation on Ceria Surfaces from DFT + U Calculations. J. Phys. Chem. C 2008, 112, 8643-8648.

(46) Da Silva, J. L. F.; Ganduglia-Pirovano, M. V.; Sauer, J.; Bayer, V.; Kresse, G. Hybrid Functionals Applied to Rare-Earth Oxides: The Example of Ceria. Phys. Rev. B 2007, 75, 045121.

(47) Aparicio-Anglès, X.; Roldan, A.; De Leeuw, N. H. Gadolinium-Vacancy Clusters in the (111) Surface of Gadolinium-Doped Ceria: A Density Functional Theory Study. Chem. Mater. 2015, 27, 7910-7917.

(48) Gerward, L.; Olsen, J. S.; Petit, L.; Vaitheeswaran, G.; Kanchana, V.; Svane, A. Bulk Modulus of $\mathrm{CeO}_{2}$ and $\mathrm{PrO}_{2}-\mathrm{An}$ Experimental and Theoretical Study. J. Alloys Compd. 2005, 400, 56-61.

(49) Henkelman, G.; Uberuaga, B. P.; Jónsson, H. Climbing Image Nudged Elastic Band Method for Finding Saddle Points and Minimum Energy Paths. J. Chem. Phys. 2000, 113, 9901-9904.

(50) Molinari, M.; Parker, S. C.; Sayle, D. C.; Islam, M. S. Water Adsorption and Its Effect on the Stability of Low Index Stoichiometric and Reduced Surfaces of Ceria. J. Phys. Chem. C 2012, 116, 7073-7082.

(51) Yang, Z.; Wang, Q.; Wei, S.; Ma, D.; Sun, Q. The Effect of Environment on the Reaction of Water on the Ceria (111) Surface : A DFT + U Study. J. Phys. Chem. C 2010, 114, 14891-14899.

(52) Matz, O.; Calatayud, M. Breaking $\mathrm{H}_{2}$ with $\mathrm{CeO}_{2}$ : Effect of Surface Termination. ACS Omega 2018, 3, 16063-16073.

(53) Fernández-Torre, D.; Carrasco, J.; Ganduglia-Pirovano, M. V.; Pérez, R. Hydrogen Activation, Diffusion, and Clustering on $\mathrm{CeO}_{2}(111)$ : A DFT+ U Study. J. Chem. Phys. 2014, 141, 014703.

(54) Carrasco, J.; López-Durun, D.; Liu, Z.; Duchoň, T.; Evans, J; Senanayake, S. D.; Crumlin, E. J.; Matolín, V.; Rodríguez, J. A.; Ganduglia-Pirovano, M. V. In Situ and Theoretical Studies for the Dissociation of Water on an Active $\mathrm{Ni} / \mathrm{CeO}_{2}$ Catalyst : Importance of Strong Metal - Support Interactions for the Cleavage of O-H Bonds. Angew. Chem. Int. Ed. 2015, 54, 3917-3921.

(55) Werner, K.; Weng, X.; Calaza, F.; Sterrer, M.; Kropp, T.; Paier, J.; Sauer, J.; Wilde, M.; Fukutani, K.; Shaikhutdinov, S.; Freund, H.-J. Toward an Understanding of Selective Alkyne Hydrogenation on Ceria: On the Impact of $\mathrm{O}$ Vacancies on $\mathrm{H}_{2}$ Interaction with $\mathrm{CeO}_{2}$ (111). J. Am. Chem. Soc. 2017, 139, 17608-17616. 
(56) Evans, M. G.; Polanyi, M. Inertia and Driving Force of Chemical. Trans. Faraday Soc. 1938, 34, 11-24.

(57) Dholabhai, P. P.; Adams, J. B.; Crozier, P.; Sharma, R. Oxygen Vacancy Migration in Ceria and Pr-Doped Ceria: A DFT+U Study. J. Chem. Phys. 2010, 132, 094104.

(58) Kozuch, S.; Shaik, S. How to Conceptualize Catalytic Cycles? The Energetic Span Model. Acc. Chem. Res. 2011, 44, 101-110.

(59) Kozuch, S. A Refinement of Everyday Thinking: The Energetic Span Model for Kinetic Assessment of Catalytic Cycles. WIREs Comput. Mol. Sci. 2012, 2, 795-815.

(60) Palmer, J. D.; Livingston, L.; Zusy, F. D. A Persistent Diurnal Rhythm in Photosynthetic Capacity. Nature 1964, 203, 1087-1088.

(61) Yang, N.; Orgiani, P.; Di Bartolomeo, E.; Foglietti, V.; Torelli, P.; Ievlev, A. V.; Rossi, G.; Licoccia, S.; Balestrino, G.; Kalinin, S. V.; Aruta, C. Effects of Dopant Ionic Radius on Cerium Reduction in Epitaxial Cerium Oxide Thin Films. J. Phys. Chem. C 2017, 121, 8841-8849.

(62) Hong, S. J.; Virkar, A. V. Lattice Parameters and Densities of Rare-Earth Oxide Doped Ceria Electrolytes. J. Am. Ceram. Soc. 1995, 78, 433-439.

(63) Fu, Q.; Halck, N. B.; Hansen, H. A.; Lastra, J. M. G.; Vegge, T. Computational Study of $\mathrm{Nb}$-Doped-SnO $/$ /Pt Interfaces: Dopant Segregation, Electronic Transport, and Catalytic Properties. Chem. Mater. 2017, 29, 1614-1649. 


\section{TOC Graphic}

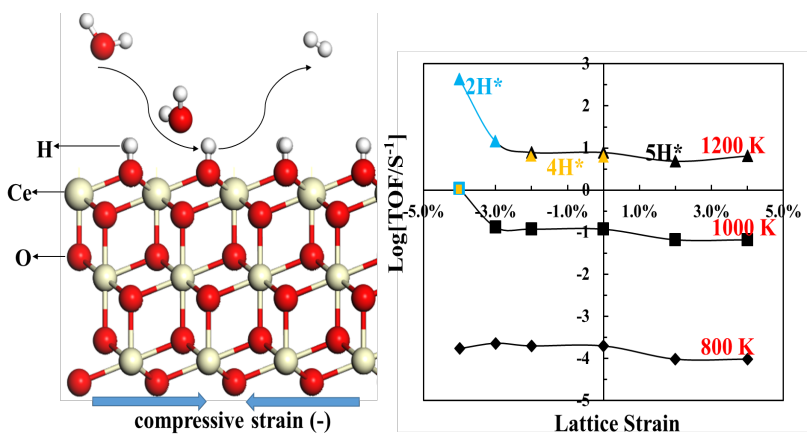

